\title{
Electron Beam Melting of Sponge Titanium
}

\author{
Hiroshi KANAYAMA, Tatsuhiko KUSAMICHI, ${ }^{1)}$ Tetsuhiro MURAOKA, ${ }^{2)}$ Toshio ONOUYE') and \\ Takashi NISHIMURA
}

Iron and Steel Research Laboratories, Kobe Steel, Ltd., Wakinohama-cho, Chuo-ku, Kobe, Hyogo-ken, 651 Japan. 1) Materials Research Laboratories, Takatsukadai, Nishi-ku, Kobe, 651-22.

Takasago, Kobe Steel, Ltd., Niihama, Arai-cho, Takasago, Hyogo-ken, 676 Japan.

2) Steel Casting and Forging Plant,

(Received on December 21, 1990; accepted in final form on March 22, 1991)

Fundamental investigations were done on electron beam (EB) melting of sponge titanium by using $80 \mathrm{~kW}$ EB melting furnace. Results obtained are as follows:

(1) To increase the melting yield of titanium in EB melting of sponge titanium, it is important to recover splashed metal by installation of water-cooled copper wall around the hearth and to decrease evaporation loss of titanium by keeping the surface temperature of molten metal just above the melting temperature of titanium without local heating.

(2) Specific power consumption of drip melting of pressed sponge titanium bar and hearth melting of sponge titanium are approximately $0.9 \mathrm{kWh} / \mathrm{kg}-\mathrm{Ti}$ and $0.5-0.7 \mathrm{kWh} / \mathrm{kg}-\mathrm{Ti}$, respectively.

(3) Ratios of the heat conducted to water-cooled mould in the drip melting and to water-cooled hearth in the hearth melting to the electron beam input power are $50-65 \%$ and $60-65 \%$, respectively.

(4) Surface defects of EB-melted ingots include rap which occurs when the EB output is excessively great, and transverse cracks when the EB output is excessively small. To prevent surface defects, the up-down withdrawal method is effective.

KEY WORDS: electron beam melting; sponge titanium; splashing; evaporation; heat balance; power consumption; solidification macrostructure; surface quality.

\section{Introduction}

Recently, the electron beam (EB) melting process has been attracting wide attention within the industry as a new titanium melting process designed to replace the vacuum arc remelting process (VAR). ${ }^{1-5)}$ The EB melting process has many advantages, such as various vacuum refining effects, effective separation of heavy inclusions, ${ }^{1)}$ and good thermal controllability.

In the U.S., using large-size EB melting furnaces, slabs of titanium are commercially manufactured directly from titanium scrap. ${ }^{2,3)}$ However, with respect to EB melting of sponge titanium, which constitutes the greater part of raw titanium material for melting, chloride contained in sponge titanium evaporates during melting and has an adverse effect on the EB gun and vacuum exhaust system. This has prevented the EB melting process from being put into commercial use. In particular, troubles in the $\mathrm{EB}$ generator caused by the entry of chloride vapour in the EB gun have caused major problems. However, new EB guns have been recently developed to reduce the influence of gas generation in the melting furnace by installing a one- or two-stage differential exhauster between the gun and the melting chamber, ${ }^{6,7)}$ and commercial use of EB melting for sponge titanium is expected.

This paper reports the results of our fundamental studies carried out on the EB melting behaviours of sponge titanium, heat transfer characteristics during melting, and the quality of EB-melted ingots in order to clarify problems encountered in applying the sponge titanium EB melting process to practical use.

\section{Experimental Method}

\subsection{Experimental EB Melting Furnace}

A small-size EB melting furnace is schematically shown in Fig. 1 and principal specifications are shown in Table 1. The EB gun has a two-stage differential exhauster which uses a diffusion pump and can irradiate electron beams stably at furance pressure below $1 \times 10^{-2} \mathrm{mmHg}$. Using an $\mathrm{EB}$ irradiation pattern controller, two kinds of irradiation patterns can be drawn with one electron beam, enabling the control of respective pattern drawing times. The melting chamber is evacuated with a diffusion pump and the pressure in the melting chamber can be controlled in the range of $10^{-6}$ to $10^{-2} \mathrm{mmHg}$ by a method designed to introduce various gases via. a pressure controller.

It is expected that a melting method combining a water-cooled copper hearth with a water-cooled copper mould will be employed for commercial EB melting furances for sponge titanium because of its refining effects. In the experimental furnace, since it is impossible to carry out melting by combining a hearth with a 
mould because of the equipment structure, experiments were conducted by dividing the process into a batch method, in which a specified amount of sponge titanium is melted in a hearth, and an ingot withdrawal method, in which raw materials are continuously fed into the mould. Round $(200 \mathrm{~mm} \phi)$ and rectangular $(150 \times 90 \mathrm{~mm})$ hearths and round $(150 \mathrm{~mm} \phi)$ and rectangular $(150 \times$ $50 \mathrm{~mm}$ ) moulds were used in strict accordance with the experiments.

The melting furnace is designed to continuously or intermittently process raw materials in the form of round bars $(-100 \mathrm{~mm} \phi)$ or granular forms $(-30 \mathrm{~mm})$. The hot-metal surface temperature was measured with a high-temperature two-color thermometer (measuring

Table 1. Specifications of the experimental EB furnace.

\begin{tabular}{|c|c|c|}
\hline EB gun & $\begin{array}{l}\text { Input power } \\
\text { Accelerating voltage } \\
\text { Beam current }\end{array}$ & $\begin{array}{l}5-80 \mathrm{~kW} \\
0-30 \mathrm{kV} \\
\text { Max. } 2.7 \mathrm{~A}\end{array}$ \\
\hline \multicolumn{2}{|c|}{$\begin{array}{l}\text { Ultimate pressure in } \\
\text { melting chamber }\end{array}$} & $1 \times 10^{-6} \mathrm{mmHg}$ \\
\hline \multicolumn{2}{|c|}{$\begin{array}{l}\text { Melting and casting } \\
\text { system }\end{array}$} & $\begin{array}{l}\text { Hearth melting } \\
\text { (Hearth size: } 200 \mathrm{~mm} \phi \times 30 \mathrm{mmh} \text {, } \\
\quad 90 \times 150 \times 30 \mathrm{mmh}) \\
\text { Withdrawal melting } \\
\text { (Ingot size: } 150 \mathrm{~mm} \phi \times 800 \mathrm{~mm} \text {, } \\
\quad 50 \times 150 \times 800 \mathrm{~mm} \text { ) }\end{array}$ \\
\hline \multicolumn{2}{|c|}{$\begin{array}{l}\text { Feeding system of raw } \\
\text { materials }\end{array}$} & $\begin{array}{l}\text { Horizontal rod feeder } \\
\quad(\text { Rod size: } 100 \mathrm{~mm} \phi \times 1000 \mathrm{~mm}) \\
\text { Vibrating granule feeder } \\
\quad(\text { Granule size: }-30 \mathrm{~mm})\end{array}$ \\
\hline
\end{tabular}

wavelengths 500 and $580 \mathrm{~nm}$ ) and a spectrometer with a visible ray range from $400-800 \mathrm{~nm}^{81}$

\subsection{Melting Materials}

For raw materials in this experiment, regular sponge titanium (B) produced by the magnesium reduction process, sponge titanium (A) with less chloride content, and sponge titanium (C) produced by the sodium reduction process were used. In addition to these, JIS No. 1 grade commercially pure titanium round bars $(100 \mathrm{~mm} \phi)$ and scrap titanium $(20-30 \mathrm{~mm}$ square $x$ $2-3 \mathrm{mmt}$ ) of the same grade were used. Table 2 shows the chemical composition of these raw materials to be melted.

Sponge titanium was used in a granular form as it is or press-formed and welded to make round bars $(100 \mathrm{~mm} \phi)$ for melting.

Tungsten powders were embedded in the proper positions of press-formed sponge titanium round bars and round titanium bars as a tracer to observe ingot pool shapes.

\subsection{Melting Experiment}

The standard melting experiment was carried out at an EB output of $60-70 \mathrm{~kW}(26-28 \mathrm{kV}, 2.2-2.7 \mathrm{~A})$ and at a furance pressure below $10^{-4} \mathrm{mmHg}$. In the experiment to investigate the effect of furnace pressure, argon and hydrogen were introduced via. a pressure controller. The chemical composition of the gas generated during melting was also investigated with a quadrupole mass spectrometer. The melting yield was determined from the change in weight before and after melting.

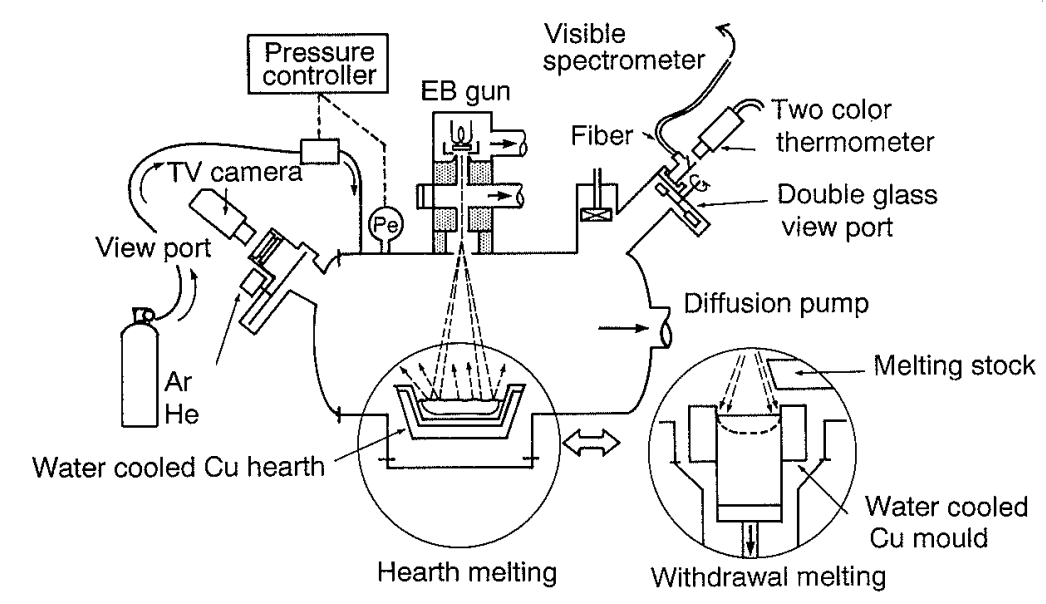

Fig. 1. Schematic diagram of experimental EB furnace used.

Table 2. Chemical composition of raw titanium materials used. (wt \%)

\begin{tabular}{lcccccccccc}
\hline Raw materials & $\mathrm{C}$ & $\mathrm{Fe}$ & $\mathrm{Si}$ & $\mathrm{O}$ & $\mathrm{N}$ & $\mathrm{H}$ & $\mathrm{Mg}$ & $\mathrm{Na}$ & $\mathrm{Cl}$ \\
\hline & $\mathrm{A}$ & 0.005 & 0.024 & 0.001 & 0.061 & 0.002 & 0.004 & 0.014 & n.d. & 0.023 \\
Sponge Ti & $\mathrm{B}$ & 0.004 & 0.030 & $<0.010$ & 0.043 & 0.003 & 0.002 & 0.026 & n.d. & 0.076 \\
& $\mathrm{C}$ & 0.006 & 0.006 & 0.002 & 0.045 & 0.001 & 0.002 & n.d. & 0.075 & 0.092 \\
\hline Ti bar & 0.009 & 0.051 & 0.004 & 0.077 & 0.005 & 0.002 & n.d. & n.d. & n.d. \\
Scrap Ti & 0.010 & 0.050 & 0.008 & 0.090 & 0.005 & 0.003 & n.d. & n.d. & n.d. \\
\hline
\end{tabular}

n.d.: Not detected 
In the experiment to investigate heat transfer characteristics during melting, the cooling water volume and water temperature at the inlet and outlet of the EB gun, melting chamber, withdrawal unit, hearth, and mould of the experimental EB furnace were measured to calculate the heat transfer rate, and based on the results the heat balance was determined.

\subsection{Method to Investigate Ingot Quality}

A round ingot $(150 \mathrm{~mm} \phi)$ melted from press-formed sponge titanium round bars under standard melting conditions was cut lengthwise and an analysis sample was collected from a specified position of the cut surface, and at the same time the section was ground and etched to observe solidified macrostructures and pool shapes.

Measurements were also taken for the depth and length of defects of longer and shorter sides of square ingots $(150 \times 150 \mathrm{~mm})$ melted from titanium round bars by varying the $\mathrm{EB}$ output and ingot withdrawal method, and the surface properties were evaluated.

\section{Experiment Results and Observation}

\subsection{Melting Yield of Sponge Titanium}

Figures $\mathbf{2}$ and $\mathbf{3}$ show melting yields, respectively, when sponge titanium, titanium round bars, and scrap titanium with varying chloride contents were melted by the ingot withdrawal melting method (round mould) and the hearth melting method (round hearth). In both melting systems, melting yield decreases with increasing chloride content in sponge titanium $(\mathrm{Mg}+\mathrm{Cl}$ or $\mathrm{Na}+\mathrm{Cl})$. This is caused by a violent molten metal splash phenomena observed during EB melting of sponge titanium.

As is clear from Table 2, chlorides such as $\mathrm{MgCl}_{2}$ or $\mathrm{NaCl}$, the removal of which has not been possible in the sponge production process, remain at levels of $300-2000 \mathrm{ppm}$ in sponge titanium. The boiling points of $\mathrm{MgCl}_{2}$ and $\mathrm{NaCl}$ are 1691 and $1738 \mathrm{~K}$, respectively, which are much lower than the melting point of titanium $\left.1948 \mathrm{~K} .{ }^{9}\right)$ During EB melting, a molten titanium layer is

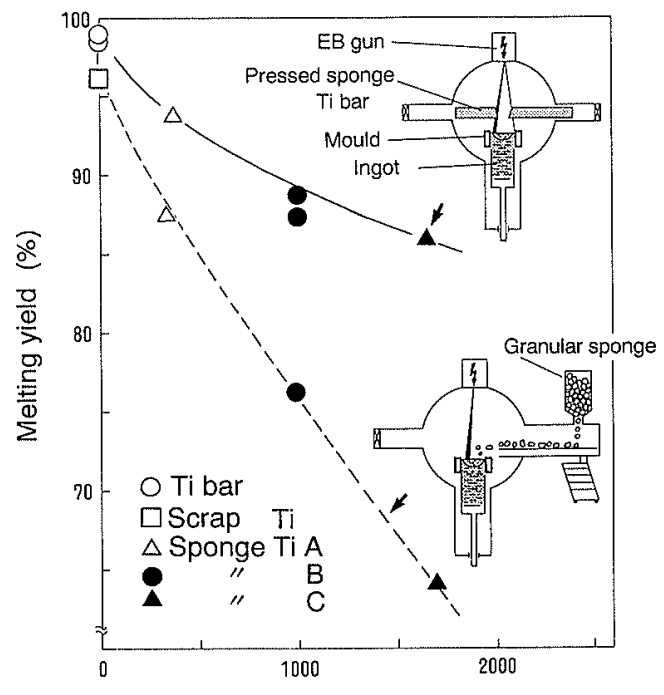

$(\mathrm{Mg}+\mathrm{Cl})$ or $(\mathrm{Na}+\mathrm{Cl})$ content in raw Ti materials $(\mathrm{ppm})$

Fig. 2. Influence of chloride content in sponge Ti on melting yield in the withdrawal melting. rapidly formed around the sponge titanium particles, and in this event, the chloride enclosed as steam in titanium sponge is rapidly released and part of the molten titanium on the periphery is blown away.

In Fig. 2, compared to the case in which press-formed sponge titanium round bars are melted, a marked decrease in melting yield is observed when sponge titanium is charged directly into hot metal. This is attributed to splashing molten droplets as large as $10 \mathrm{~mm}$ in diameter since the molten titanium bath around sponge titanium is blown away when sponge titanium is melted in the molten titanium bath, whereas when EB is irradiated directly to sponge titanium for melting, the molten titanium layer thickness formed is as thin as 1-2 mm and the splashed droplets are as small as around $1 \mathrm{~mm}$ in diameter and are uniform.

The hearth melting method is considered to be superior as a commercial EB furnace in respect to its refining effects. The molten metal splashing phenomena when

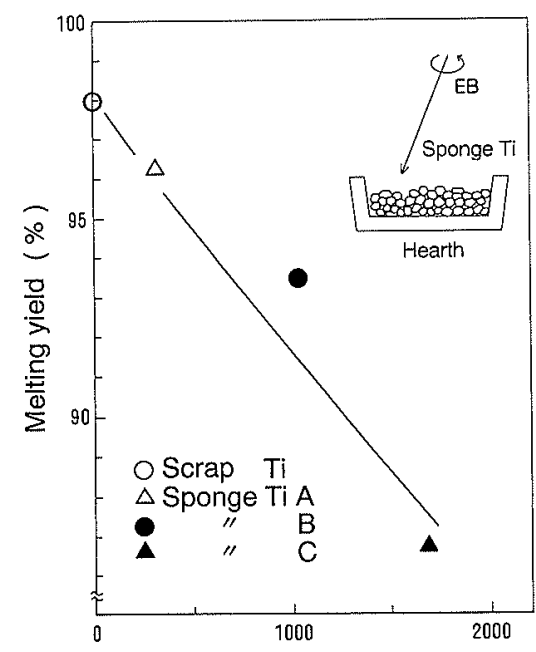

$(\mathrm{Mg}+\mathrm{Cl})$ or $(\mathrm{Na}+\mathrm{Cl})$ content in raw Ti materials $(\mathrm{ppm}$

Fig. 3. Influence of chloride content in sponge Ti on melting yield in the hearth melting.

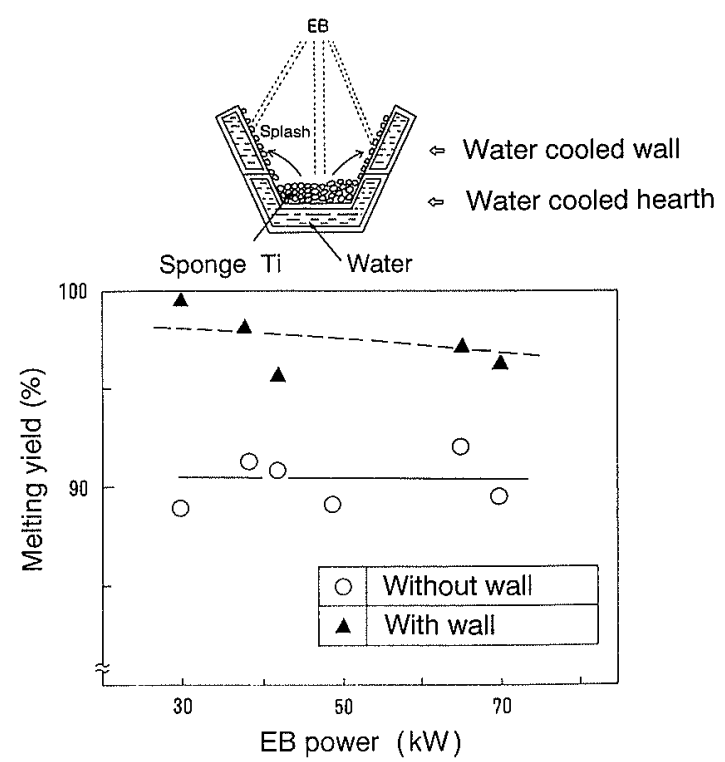

Fig. 4. Increase in melting yield during melting of sponge $\mathrm{Ti}(\mathrm{B})$ in the hearth with water-cooled wall. 
sponge titanium is melted in a hearth was quantitatively investigated with a molten metal splashing model. The results indicated that all the splashed molten metal can be collected with a water-cooled copper wall $200 \mathrm{~mm}$ or higher, which is installed around the hearth. ${ }^{10)}$

The melting of sponge titanium (B) was carried out in a rectangular water-cooled hearth with a $200 \mathrm{~mm}$-high water-cooled copper wall installed on the periphery of the hearth and the splashed molten metal was collected by the water-cooled copper wall. Figure 4 shows the melting yield when molten titanium droplets adhering to the water-cooled copper wall are irradiated with electron beams, which are controlled to an energy density that does not erode water-cooled cooper. Installation of a water-cooled copper wall and melting and recovering the splashed molten metal have improved the melting yield by $7 \%$.

\subsection{Evaporation Loss of Titanium}

When a titanium round bar or scrap titanium is melted, no splashed molten metal is observed. The reason why the melting yield does not reach $100 \%$ even in a case such as that shown in Fig. 3 is primarily due to the evaporation loss of titanium from molten metal.

At first, the influence of molten metal surface temperature on evaporation loss was investigated. The EB irradiation output was varied in a round water-cooled hearth and scrap titanium was melted for $20 \mathrm{~min}$. The relationship between molten metal surface temperature and molten metal yield is shown in Fig. 5. Titanium rapidly evaporates as the molten metal surface temperature rises.

Next, the influence of furnace pressure on evaporation loss was investigated. Figure 6 shows the melting yield when the furnace pressure was varied in three steps by introducing argon or hydrogen via. a pressure controller and the EB irradiation output was also varied in three

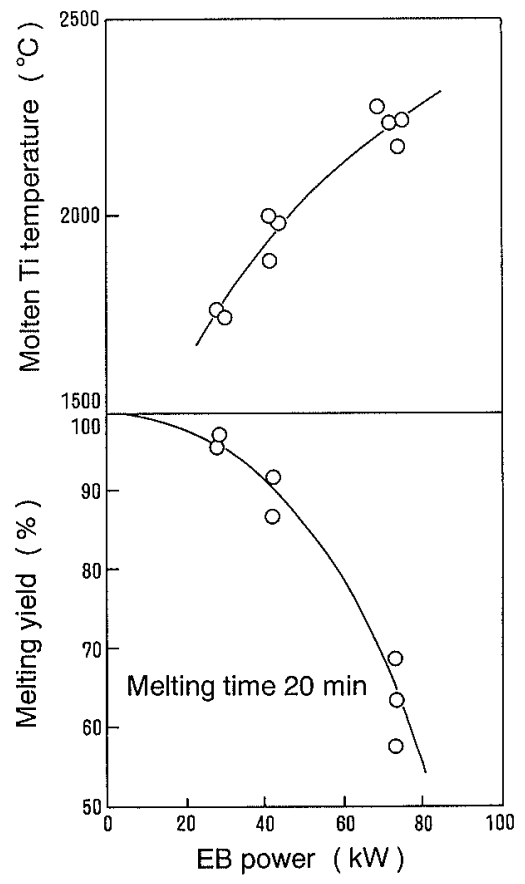

Fig. 5. Influence of molten Ti temperature on melting yield during melting of scrap $\mathrm{Ti}$ in the hearth. steps of 28,42 , and $72 \mathrm{~kW}$ to melt scrap titanium in a round water-cooled hearth and held for $20 \mathrm{~min}$. Evaporation loss slightly decreases as furnace pressure rises, but it is not as effective as temperature drop.

From these results, it is important to keep molten metal surface temperature just above the titanium melting point without localized temperature rise after melting of raw materials in order to reduce evaporation loss in EB melting of titanium.

\subsection{Power Consumption in Melting}

First, the power consumption during EB melting was investigated through round ingot withdrawal melting using three types of sponge titanium press-formed round bars $(100 \mathrm{~mm} \phi)$ as melting materials. The amount of beam power irradiated to the round bars was calculated as the product of total beam power and the irradiation time ratio to the round bar of the irradiation pattern, and is shown in Fig. 7 as the relationship with round-bar melting rate. The melting rate is nearly proportional to irradiation power irrespective of the type of sponge titanium. According to the above results, about $0.9 \mathrm{kWh} / \mathrm{kg}$ was obtained for the specific power consumption required for melting the press-formed sponge titanium round bars, and it is about twice the specific theoretical power consumption $\left.(0.42 \mathrm{kWh} / \mathrm{kg}) .{ }^{11}\right)$ This is attributed to large heat loss caused by radiation from the round

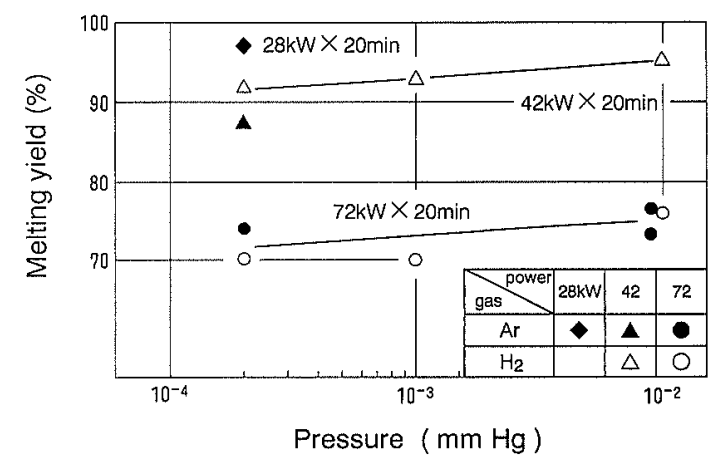

Fig. 6. Influence of pressure controlled by gas introduction in the melting chamber on melting yield during melting of scrap $\mathrm{Ti}$ in the hearth.

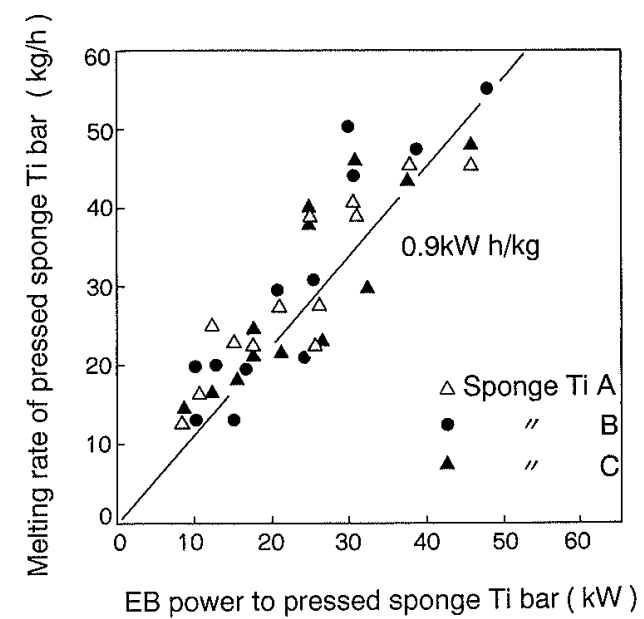

Fig. 7. Relation between melting rate of pressed sponge $\mathrm{Ti}$ bar and EB power irradiated to pressed sponge Ti bar in the withdrawal melting. 
bar tip end fusing zone and by the conduction to the round bars.

Next, sponge titanium is charged into a rectangular water-cooled hearth. Using a quadruplicate rectangular beam pattern it is then heated at varying $E B$ outputs in order to uniformly heat the top surface of the hearth burden. The relationship between the time required to melt down the overall surface area and the EB irradiation power density is shown in Fig. 8. This figure indicates a given relationship irrespective of sponge titanium types. At this point, the relationship between the EB irradiation power density and the time required for melting was found from a simple melting model ${ }^{10)}$ and plotted in a solid line in Fig. 8, which shows good agreement with actually measured values. According to these results, $0.5-0.7 \mathrm{kWh} / \mathrm{kg}$ was obtained as the specific power consumption required to melt sponge titanium in a hearth in which titanium hot metal is not present.

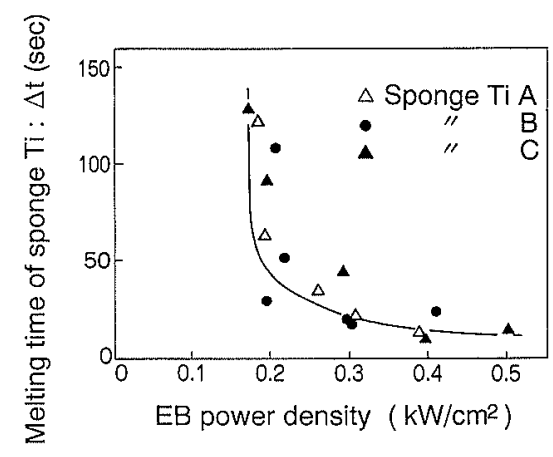

Fig. 8. Relation between melting time of sponge Ti and EB power density in the hearth melting.

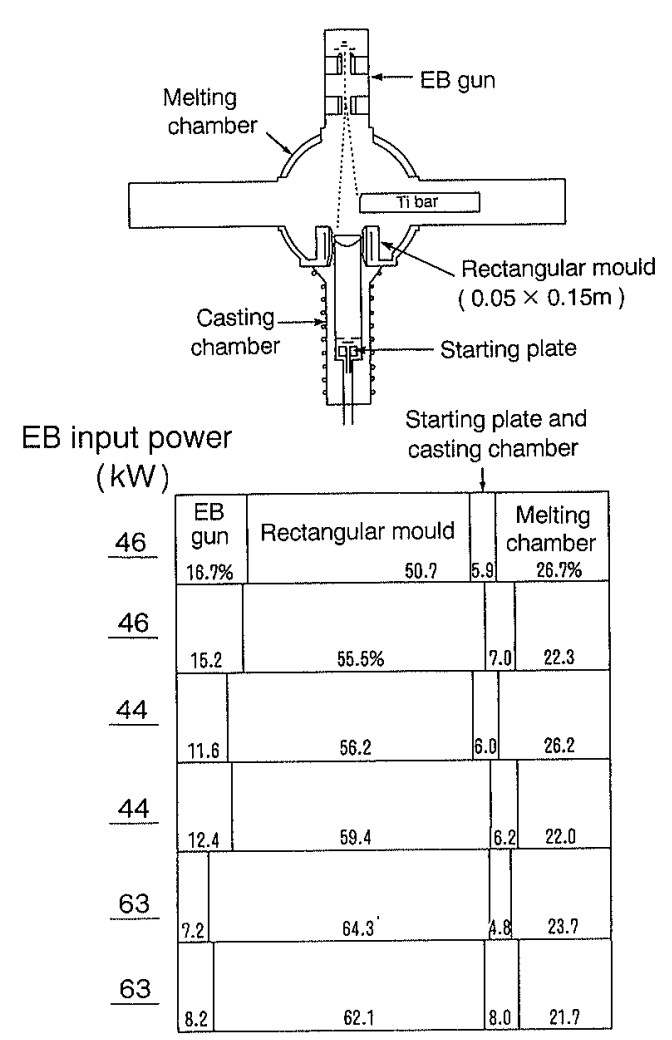

Fig. 9. Heat balance during melting of Ti bar and casting of rectangular ingot in the withdrawal melting.

\subsection{Heat Transfer Characteristics during EB Melting}

In order to investigate heat transfer characteristics during EB melting, heat balance was measured in both ingot withdrawal melting and hearth melting. The total heat transfer fed into cooling water of each EB furnace portion in ingot withdrawal melting is found to be $90-110 \%$, suggesting that nearly all output power is transferred to cooling water, though in great variations. Because the ingot withdrawal speed of this experiment is as slow as $4-12 \mathrm{~mm} / \mathrm{min}$, it is believed that the effect of heat reserve in ingots would be small. Figure 9 shows the results of determining the ratio of heat transfer fed to each furnace cooled portion to the total heat transfer fed to cooling water. Heat loss at the EB gun is about $7-17 \%$, the ratio of heat transferred from hot metal surface to furnace wall by radiation is $22-27 \%$, and that to water-cooled copper mould by conduction is $50-65 \%$, the largest of all.

Figure 10 shows the measurement results of heat balance when sponge titanium (B) was melted in a round hearth. This also indicates that the ratio of overall heat transfer fed to cooling water to EB output is about the same as that in ingot withdrawal melting. The ratio of heat transfer fed to the hearth was $60-65 \%$, nearly equivalent to that in ingot withdrawal melting. According to the heat transfer rate to the hearth, which was found from the increase in hearth cooling water temperature, the molten titanium surface temperature, and the hearth cooling water temperature, the overall heat transfer coefficient between titanium and hearth cooling water in the hearth inner area was calculated and plotted against the molten titanium temperature and is shown in Fig.

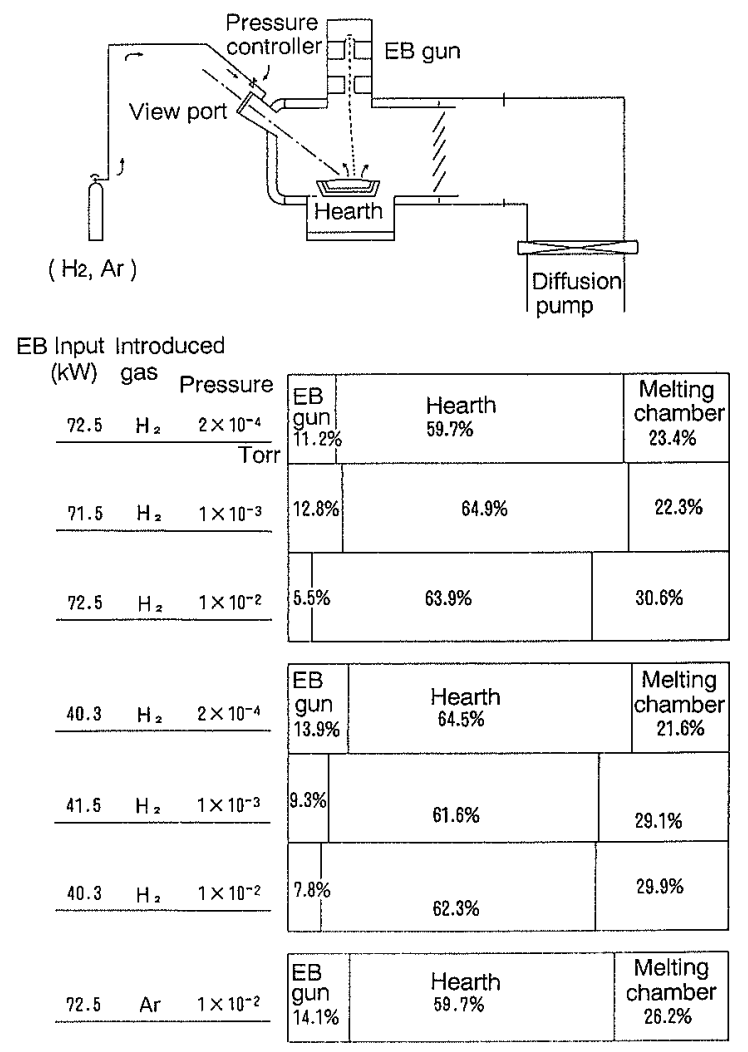

Fig. 10. Heat balance during melting of sponge $\mathrm{Ti}(\mathrm{B})$ in the hearth melting. 


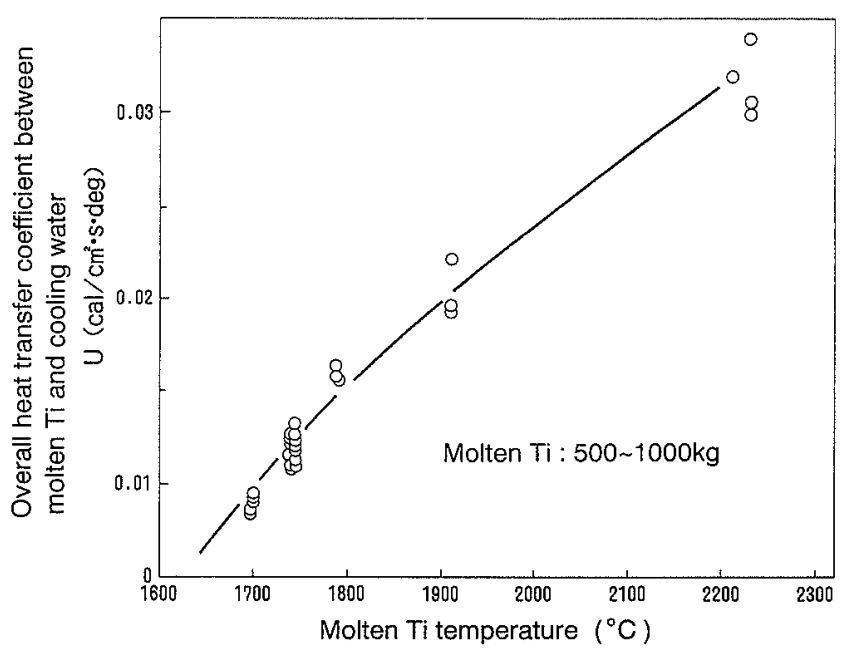

Fig. 11. Change in overall heat transfer coefficient between molten Ti and cooling water in the hearth melting.

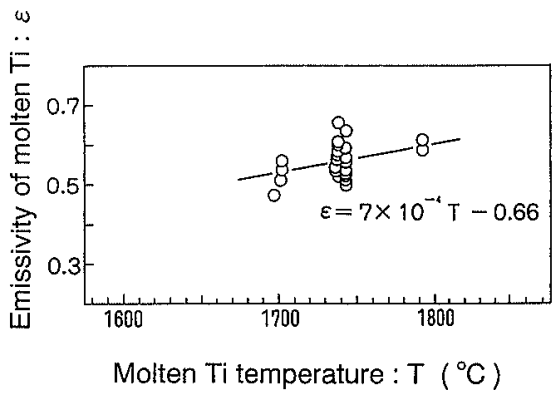

Fig. 12. Emissivity of molten Ti calculated from heat balance in the hearth melting.

11. The overall heat transfer coefficient obtained was around $0.01-0.03 \mathrm{cal} / \mathrm{cm}^{2} \cdot \mathrm{sec} \cdot \mathrm{K}$, which is nearly the same as the overall heat transfer coefficient ${ }^{12)}$ already obtained between the slag bath and copper mould cooling water in the electroslag remelting process.

The emissivity of molten titanium, calculated from measurement results of the heat transferred to the furnace cooling water by radiation, and the hot metal surface temperature in hearth melting are shown in Fig. 12. A value of around 0.5-0.7 was obtained, which indicates the negligible effect of hot metal surface temperature.

\subsection{Change in Chemical Composition of EB-melted Ingots}

Using press-formed sponge titanium round bars and titanium round bars, round ingots $(150 \mathrm{~mm} \phi)$ were melted by the ingot withdrawal method under standard conditions and investigations were made on the change in chemical composition of the ingots before and after melting.

Figure 13 shows analytical values of various components of the top, middle, and bottom portions at the ingot center and periphery. The alternate long and short dash lines in the figure show the analytical values of raw materials. The change in oxygen and nitrogen before and after melting is similar to that in VAR, and hydrogen is $1 \mathrm{ppm}$ or less, exhibiting a higher refining effect than in VAR.

In order to investigate the effect of initial vacuum in

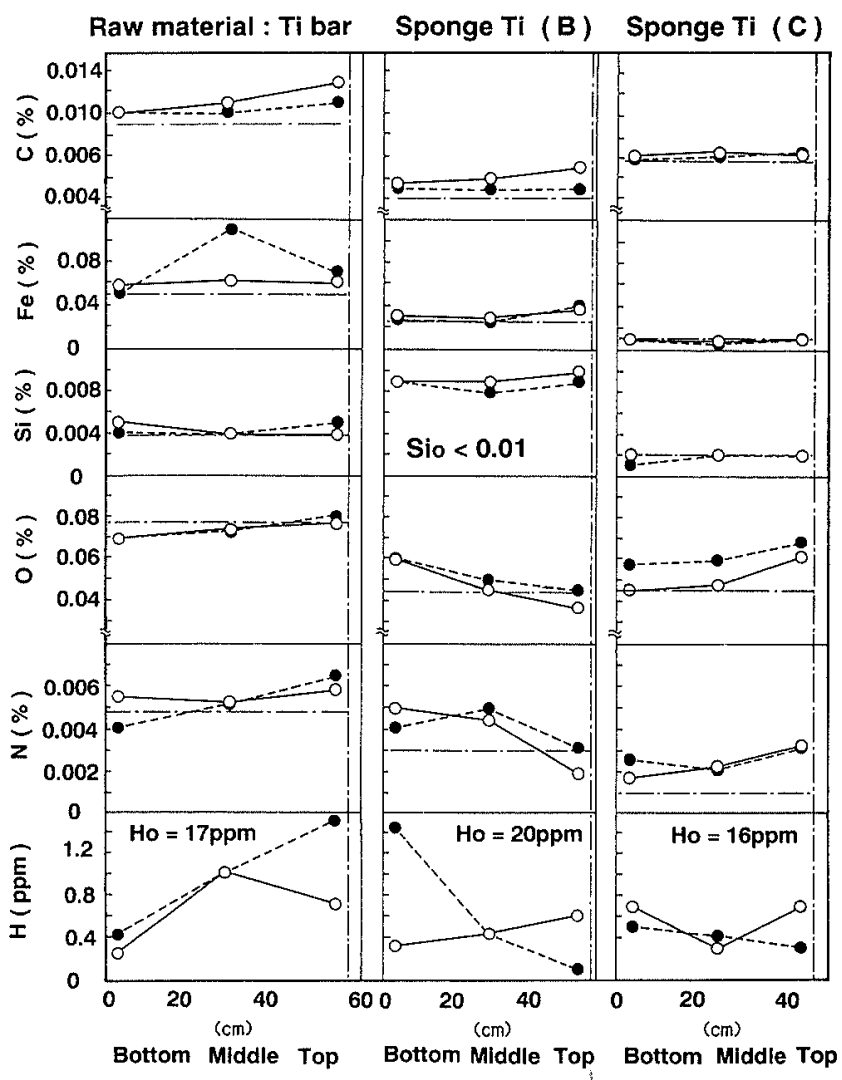

Fig. 13. Change in chemical composition of EB-melted ingots along height.

$\mathrm{Si}_{0}$ : initial content of $\mathrm{Si}, \mathrm{H}_{\mathbf{o}}$ : initial content of $\mathrm{H}$

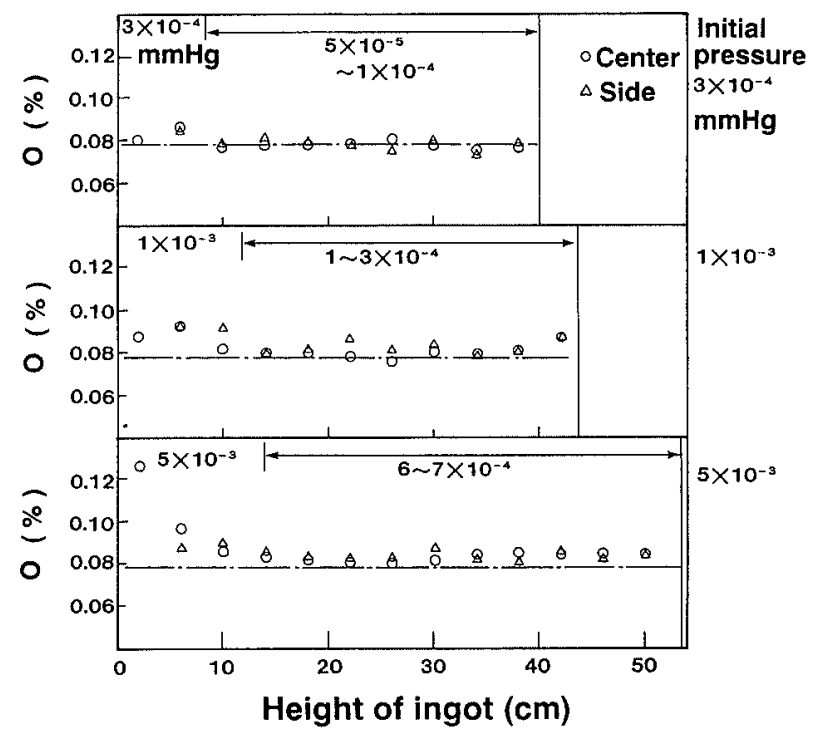

Fig. 14. Influence of initial pressure in melting chamber on oxygen pickup of EB-melted ingot.

a furnace on the increase of oxygen and nitrogen in ingots, the initial ultimate vacuum in the furnace was adjusted and titanium round bars were melted into round ingots, on which similar investigations were made. Figures 14 and 15 show changes in oxygen and nitrogen contents in the ingot height direction, respectively. If the initial vacuum is poor, oxygen and nitrogen pickups are conspicuous at the ingot bottom. Figure 16 shows the measurement results of changes in the vacuum atmosphere gas composition in the melting process with 
a quadrupole mass spectrometer. Hydrogen emission and nitrogen absorption occur as titanium melting takes place. With respect to nitrogen, it is assumed that primarily the titanium atom which has been evaporated absorbs nitrogen.

With the foregoing description, the increase in oxygen has a small effect when the initial vacuum is $1 \times 10^{-2} \mathrm{mmHg}$ or less, indicating that it is important to maintain $7 \times 10^{-4} \mathrm{mmHg}$ or less to prevent the increase

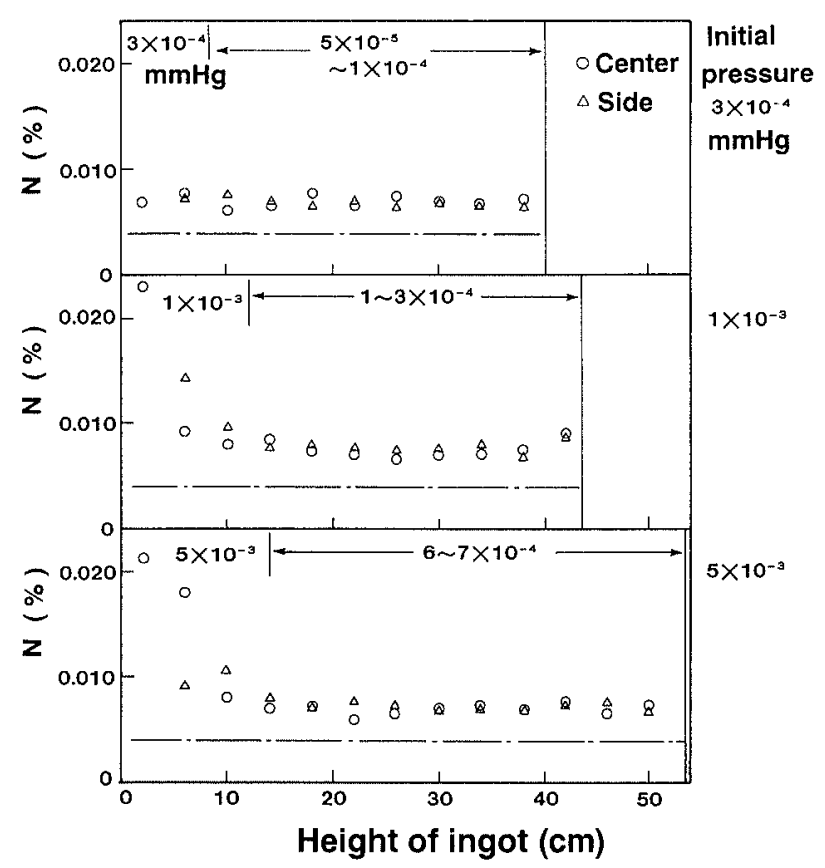

Fig. 15. Influence of initial pressure in the melting chamber on nitrogen pickup of EB-melted ingot. in nitrogen.

Figure 17 shows the macrostructure of round ingots $(150 \mathrm{~mm} \phi)$ produced from titanium round bars in which the tracer tungsten powders were embedded in proper positions. From bottom to top, a columnar structure is developed, exhibiting a good cast structure with unidirectional solidification. From the undissolved tungsten powder distribution, the pool shape can be observed, and it was confirmed that the pool depth was extremely shallow, about $1 / 2$ to $1 / 3$ the mould diameter.

\subsection{Surface Quality of EB-melted Ingots}

It is possible to produce good quality titanium strip coil when defects of casted titanium slab surface are shaven by machine tools before the hot strip rolling. To reduce yeild loss of titanium by shaving, the surface properties of casted titanium slab surface are important.

Square ingots $(150 \times 50 \mathrm{~mm})$ were melted from titanium round bars and the surface properties were investigated. The ratio of the electron beam irradiation time of round bars to that in the mould is kept constant at $1: 3$ and the irradiation time ratio of longer to shorter sides in the mould to $1: 4$. In this process the EB output and ingot withdrawal method were varied.

Figure 18 shows the relationship between the defect depth of the ingot surface and the number of defects when the EB output was varied in the intermittent withdrawal method. Surface defects are aggravated as the EB output increases and decreases, and there should be an optimum EB output that minimizes defects. If the EB output is excessively high, defective rapping occurs, whereas if it is excessively low, transverse cracks and irregularities occur at the corners. Figure 19 shows typical

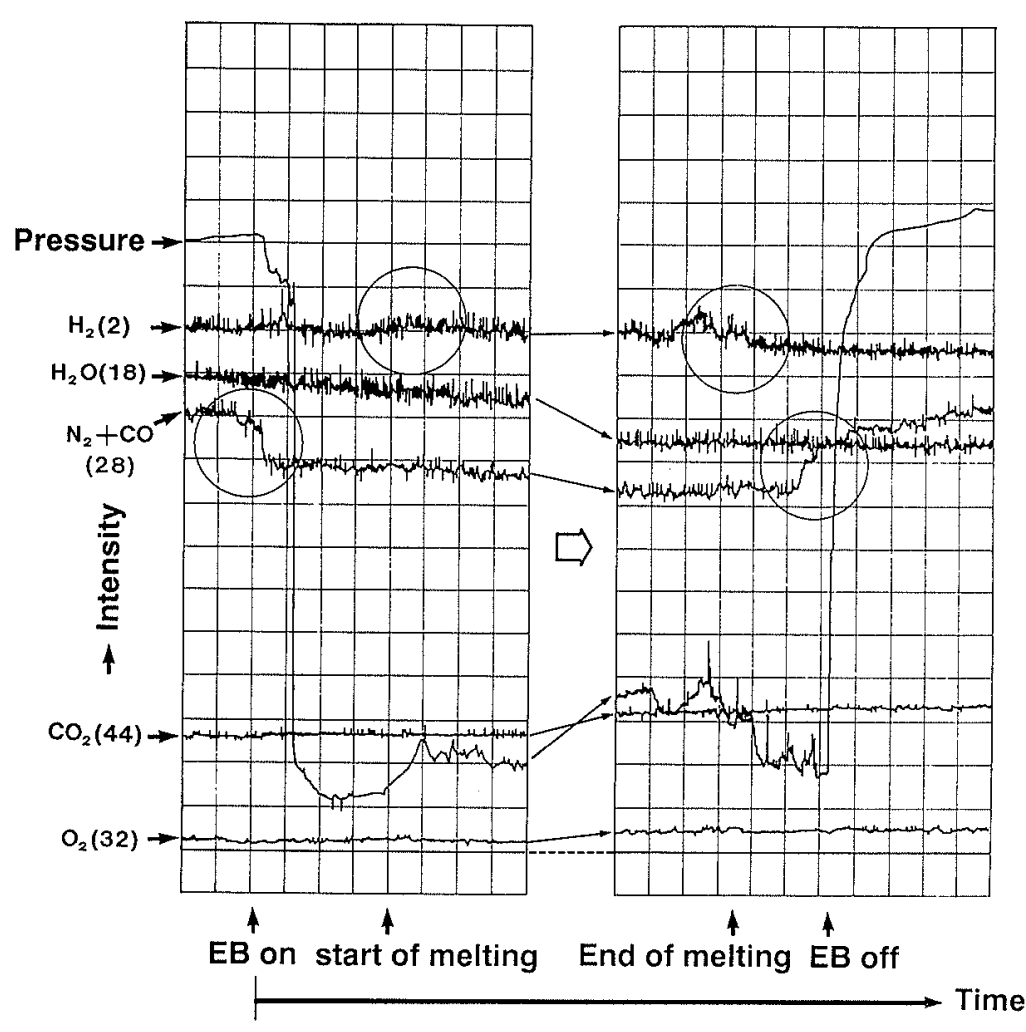

Fig. 16. Change in pressure and gas compositions measured by quadrupole mass spectrometer during EB melting.

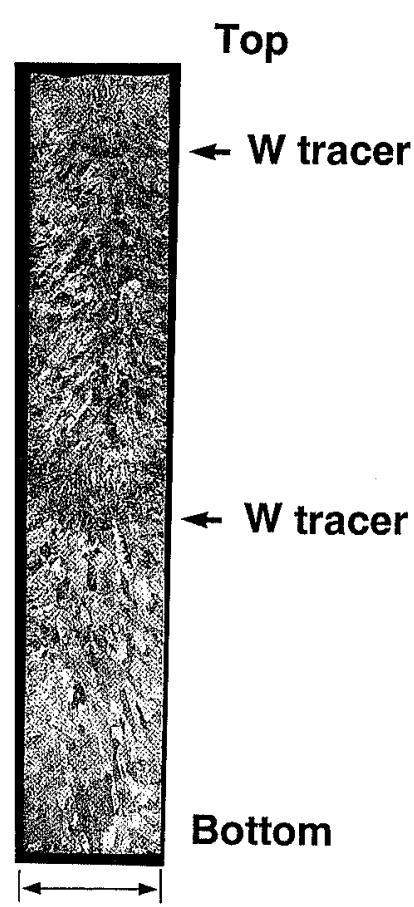

\section{$150 \mathrm{~mm}^{\phi}$}

Fig. 17. Macrostructure of EB-melted ingot. 


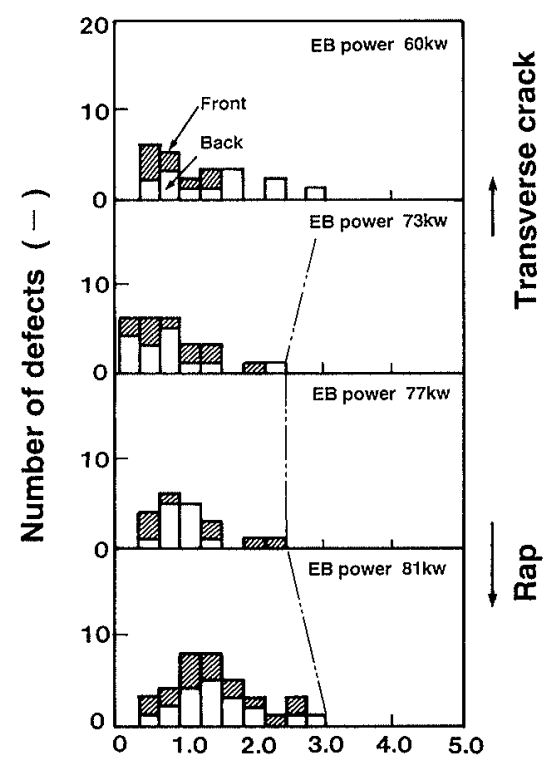

Depth of surface defect $(\mathrm{mm})$

Fig. 18. Influence of EB output on surface defect.

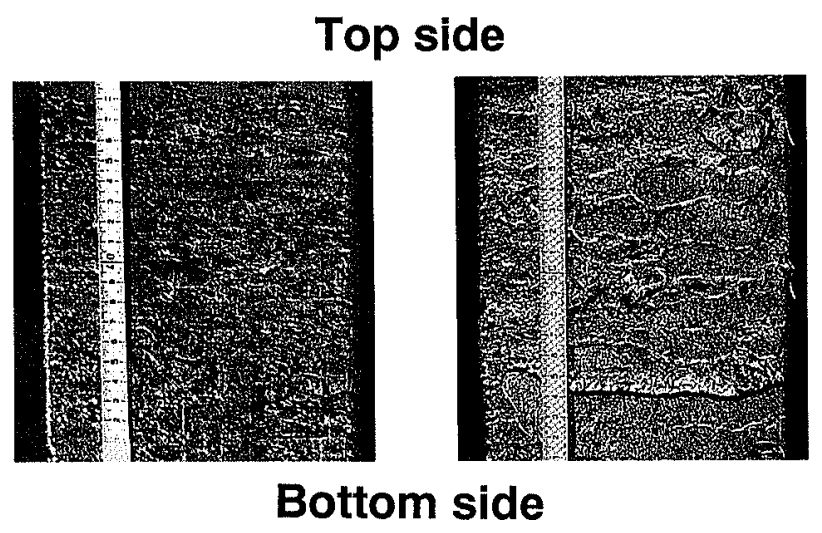

\section{Good surface}

Rap defect

Fig. 19. Typical defect of rap and good surface of square ingots.

defective rapping compared with a good surface.

Next, the effect of the ingot withdrawal method was investigated. First, continuous and intermittent withdrawal methods were compared. Continuous withdrawal sometimes generates a huge defect exceeding $20 \mathrm{~mm}$ in width, indicating the superiority of the intermittent withdrawal method.

Then, investigations were made on the effect of the up-down method, in which the ingot is slightly pushed up once then withdrawn downward. Figure $\mathbf{2 0}$ compares the regular intermittent withdrawal method with the up-down method. Under either conditions, defects can be improved by the up-down method.

\section{Conclusion}

Fundamental investigations were made on the EB melting behaviour of sponge titanium and EB-melted ingot quality using a small-size EB melting furnace. The obtained results include the following:

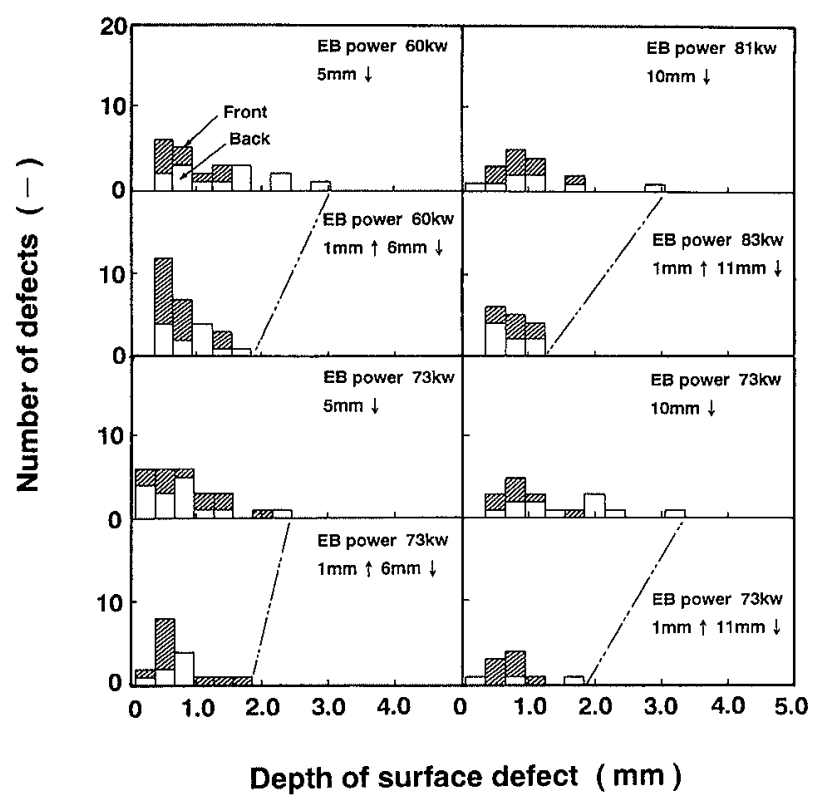

Fig. 20. Influence of up-down withdrawal method on surface defect.

(1) The lowered yield in EB melting of sponge titanium is attributed to molten titanium splashing and titanium evaporation loss during sponge titanium melting. The yield can be improved by collecting almost all splashed molten titanium with a wall about $200 \mathrm{~mm}$ high.

(2) To prevent evaporation loss from molten titanium, it is essential to control molten metal surface temperature just above the titanium melting point while preventing a localized temperature increase after melting of raw materials.

(3) The power consumption rate required for EB melting of only press-formed sponge titanium round bars is about $0.9 \mathrm{kWh} / \mathrm{kg}$, whereas that required for melting sponge titanium charged into the hearth is about $0.5-0.7 \mathrm{kWh} / \mathrm{kg}$.

(4) The increase in oxygen and nitrogen of EBmelted ingots is nearly equivalent to VAR-produced ingots, but the hydrogen content is significantly lower compared to VAR.

(5) Surface defects of EB-melted ingots include rapping, which occurs when the EB output is excessively high, and transverse cracks, which occur when the EB output is excessively low. To prevent surface defects, the up-down withdrawal method in which ingots are pushed up once, then withdrawn downward is determined to be effective.

\section{REFERENCES}

1) C. H. Entrekin: Electron Beam Melting and Refining State of the Art, Bakish Materials Corp., NJ, (1985), 40.

2) L. C. Hainz, II: Electron Beam Melting and Refining State of the Art, Bakish Materials Corp., NJ, (1983), 191.

3) H. R. Harker and C. H. Entrekin: Titanium, (1986), 939.

4) R. N. Jarrett: Electron Beam Melting and Refining State of the Art, Bakish Materials Corp., NJ, (1986), 332.

5) S. Fukumoto, N. Nakao, M. Fuji and H. Takeuchi: Electron Beam Melting and Refining State of the Art, Bakish Materials Corp., NJ, (1989), 100.

6) J. A. Knecht, II and H. R. Harker: Electron Beam Melting and 
Refining State of the Art, Bakish Materials Corp., NJ, (1984), 175 .

7) H. Ranke, V. Bauer, W. Dietrich, J. Heimerl and H. Stephan: Electron Beam Melting and Refining State of the Art, Bakish Materials Corp., NJ, (1985), 77.

8) T. Kusamichi, H. Kanayama, H. Matsuzaki and T. Onouye: Electron Beam Melting and Refining State of the Art, Bakish Materials Corp., NJ, (1989), 137.
9) O. Kubaschewski and C. B. Alcock: Metallurgical Thermochemistry, Pergamon Press, New York, (1979), 151.

10) H. Kanayama, T. Kusamichi, T. Muraoka, T. Onoye and T. Nishimura: Tetsu-to-Hagané, 77 (1991), 512.

11) I. Barin and O. Knacke: Thermochemical Properties of Inorganic Substances, Springer-Verlag, Berlin (1973), 749.

12) T. Kusamichi, T. Isii, T. Onouye and K. Narita: Tetsu-to-Hagané, 66 (1980), 749 . 